\title{
Empirical Analysis on Development Efficiency and Influencing Factors of China's Provincial Real Estate
}

\author{
Zhigao Liao \\ Department of Management \\ Guangxi University of Science \& Technology \\ Liuzhou, 545006, China
}

\author{
Yan Liao \\ Department of Management \\ Guangxi University of Science \&Technology \\ Liuzhou, 545006, China
}

\begin{abstract}
Taking the real estate development enterprises in China's 31 provinces and cities as research object, we have applied the Super Efficiency DEA model to measure their technical, pure technical efficiency, scale efficiency and inter-annual change trend between 2007 and 2011 in this dissertation. Using the Truncated Regression (Tobit) model, we identify the influence of different factors on the efficiency. The empirical results show that the development efficiency of real estate in our country average of $\mathbf{0 . 8 5 5 8}$, namely the efficiency in the average level; the difference of the real estate development efficiency in China's 31 provinces and cities is big; east, central and western regions development efficiency level gap is narrowing; efficiency of various provinces and cities in the region is different; government support, scale of real estate, external demand and production elements configuration has a significant positive effect on development level of efficiency.
\end{abstract}

Keywords-real estate; development efficiency; SE-DEA; Tobit; influencing factors

\section{INTRODUCTION}

Since China's reform and opening up, the market economy in our country has penetrated into the various fields of national economy, not only boost the rapid development of national economy, but also increased the efficiency of our country's economy. It revealed in the real estate industry fully. At the same time, with the rapid development of real estate industry, it appeared some non-standard problem such as development "overheating", and "bubble". What is the reason? Does real estate development speed contradict with the real estate market demand, which make real estate deviated from its value, then eventually led to the emergence of these problems? Therefore, the author supposes it is necessary to measure and analyze current development efficiency of the real estate and influence factor.

Due to the different research emphasis on the real estate industry at home and abroad, foreign scholars Lewis, Anderson (1999) using the Bayesian method to explore the efficiency of real estate enterprises; Wei, Wang (2007) using the data envelopment analysis method to measure real estate performance efficiency. And domestic scholars use the DEA method to measure the efficiency of real estate enterprise; Yuming, Lilian (2001) proposed by the present value method to quantify the efficiency of the real estate market. And domestic scholars use the DEA method to measure the efficiency of real estate enterprise, Zhou Chuohua etc. (2007)
Taking the transformation of the real estate industry listed companies as the research object, using DEA method to calculate the company's business performance stability index before and after the transformation and compare the mean performance; Meng Chuanjin etc. (2008) Based on DEA method for the relative effectiveness evaluation on the cross section data of real estate enterprises; Zheng Junjun etc. (2013) Based on DEA-Malmquist index measure China's provincial from 1997 to 2008 real estate development enterprises total factor productivity changes.

Existing literature on the efficiency of real estate and influence factors analysis is used for reference, However, the following problems still need to be improved: 1)The existing literature mostly select listed real estate company's financial data, but few documents analyze provincial real estate efficiency ; 2) There are few literatures to correlation index, the multicollinearity and other quantitative analysis; 3) Most of the existing literature use the CCR-DEA model and the BBC-DEA model to calculate the efficiency value, these models can't distinguish between efficiency and effective decision-making unit. In view of this, this paper uses the SE-DEA model and the Tobit to analysis China's provincial real estate development efficiency and influencing factors.

\section{RESEARCH METHOD AND DATA SOURCE}

\section{A. Research method}

DEA improved model -the Super Efficiency (SE-DEA) makes up the traditional CCR-DEA model and BBC-DEA model for multiple simultaneous effective decision-making unit can't make further evaluation and comparison of the defect, so that between effective decision-making unit can be compared.

Assume that there are $\mathrm{n}$ independent decision-making unit (DMU), the $\mathrm{j}$ DMU has $\mathrm{m}$ kind of resource input $\mathrm{x}$ and $\mathrm{s}$ kind of output $y, t$ it is the basic idea of SE-DEA model: during the $j$ DMU efficiency evaluation, so that the input and output of the j DMU would be replaced by all other inputs and outputs of decision-making unit a linear combination, so the $j$ decision-making unit will be excluded, avoiding the traditional DEA model for multiple simultaneous effective decision-making unit cannot be further compare defects. Super Efficiency DEA model is: 
$\operatorname{Min} \theta_{0}$

$$
\begin{gathered}
\text { s.t. } \sum_{j=1}^{n} \lambda_{j} x_{j i}+s_{i}^{-}=\theta_{0 x_{i 0}} i=1,2, \cdots, m \\
\sum_{\substack{j=1 \\
j=j_{0}}}^{n} \lambda_{j} y_{j r}-s_{r}^{+}=y_{r 0} r=1,2, \ldots, s \\
\lambda_{j} \geq 0, j=1,2, \cdots, n \\
s_{r}^{+} \geq 0, s_{i}^{-} \geq 0
\end{gathered}
$$

In the formula, $\theta_{0}$ is the efficiency value of decision-making unit, $\lambda_{j}$ which relatives to DMU0 is $j$ decision-making unit combination proportion in an reconstruct effective DMU combination. $s_{r}^{+}, s_{i}^{-}$is slack variable. When $\theta_{0} \geq_{1}, s_{r}^{+}=s_{i}^{-}=0$, DMU0is the DEA effective technology, The formation of the efficient frontier surface is constant returns to scale, and decision-making unit is technology

effectively and scale efficiently, $\quad \theta_{0} \underset{\substack{j=1 \\ j \neq j_{0}}}{\text { when }} \theta_{0} \leq 1$

$$
k=\frac{1}{\theta_{0}} \cdot \sum_{\substack{j=1 \\ j \neq j_{0}}}^{n} \lambda_{j} \quad \theta_{0} \leq 1
$$

or $s_{r}^{+} \neq 0, s_{i}^{-} \neq 0$, the decision-making unit is not effective, if $s_{r}^{+}=s_{i}^{-}=0$, the technology effectively, when $\mathrm{k}=1$, the decision-making unit is the constant return to scale; when $\mathrm{k}<1$, the decision-making unit is the increasing return to scale; when $\mathrm{k}>1$, the decision-making unit is the decreasing return to scale.

\section{B. Data source}

\section{1) The setting of input / output variables}

According to the existing literature, this paper selects the variables as follows: the annual invested amount (X1) as capital input; the annual land acquisition area (X2) as land input; the number of employees (X3) as human input; the main business income (Y1) and the annual completed housing area (Y2) as outputs.

\section{2) The choice of sample}

This article selected samples during 2007-2011, using the algorithm of geometric average to obtain its five-year average, avoid the interference of the volatility of its data. Sample subject is our 31 provinces and cities. Using the data from 《China statistical yearbook》 and 《China real estate yearbook》.

\section{RESULT OF THE MODEL AND ANALYSIS}

\section{A. Based on SE-DEA model development efficiency measure}

\section{1) The pretreatment of input and output variables}

a) The Correlation analysis

In this paper, using SPSS16.0 software, carrying on Pearson correlation analysis for the selected input and output variables, at the 0.01 level of confidence, five years of variable data correlation analysis results show that all between input and output variables are positively related, and most of the variables at the 0.01 level of confidence are significantly correlation, meet the SE-DEA analysis evaluation of the basic requirements.

b) The Multicollinearity analysis

In the analysis of correlation between the input and output variables, the selection of three input variables, and the correlation coefficient was around 0.7-0.8, therefore, these variables may exist the Multicollinearity. Using the Tolerance (Tolerance) and the variance inflation factor (Variance Inflation, VIF) indicators of the SPSS16.0 software to inspect whether these three independent variables exist Multicollinearity, specific results show that the Tolerance of three input variables are greater than 0.1 , you can roughly determine the Multicollinearity between them is not a serious problem, you can proceed to the SE-DEA analysis.

c) The SE-DEA analysis

Using EMS 1.3 software to calculate efficiency value, the

\begin{tabular}{|c|c|c|}
\hline Area & $\mathrm{TE}$ & $\mathrm{SE}$ \\
\hline Beijing & 0.8363 & Irs \\
\hline Tianjin & 1.0681 & - \\
\hline Hebei & 0.6045 & drs \\
\hline Shanxi & 0.7278 & $\mathrm{drs}$ \\
\hline Inner Mongolia & 0.6803 & drs \\
\hline Liaoning & 0.9254 & drs \\
\hline Jilin & 0.7165 & $\mathrm{drs}$ \\
\hline Heilongjiang & 0.9193 & $\mathrm{drs}$ \\
\hline Shanghai & 2.2225 & - \\
\hline Jiangsu & 1.2548 & - \\
\hline Zhejiang & 0.8473 & irs \\
\hline Anhui & 0.5894 & $\mathrm{drs}$ \\
\hline Fujian & 0.6016 & $\mathrm{drs}$ \\
\hline Jiangxi & 0.8449 & $\mathrm{drs}$ \\
\hline Shandong & 0.6865 & $\mathrm{drs}$ \\
\hline Henan & 0.7517 & drs \\
\hline Hubei & 0.6986 & drs \\
\hline Hunan & 0.8190 & drs \\
\hline Guangdong & 0.7398 & $\mathrm{drs}$ \\
\hline GuangXi & 0.5306 & drs \\
\hline Hainan & 0.5484 & irs \\
\hline Chongqing & 0.7443 & $\mathrm{drs}$ \\
\hline Sichuan & 0.9462 & $\mathrm{drs}$ \\
\hline Guizhou & 0.7111 & $\mathrm{drs}$ \\
\hline Yunnan & 0.5700 & $\mathrm{drs}$ \\
\hline Tibet & 1.3953 & - \\
\hline Shanxi & 0.4917 & irs \\
\hline Gansu & 0.7148 & drs \\
\hline Qinghai & 0.9723 & $\mathrm{drs}$ \\
\hline Ningxia & 1.3195 & - \\
\hline Xinjiang & 1.0503 & - \\
\hline Eastern region & 0.9055 & drs \\
\hline Central region & 0.7497 & drs \\
\hline Western region & 0.8916 & drs \\
\hline Nation & 0.8558 & $\mathrm{drs}$ \\
\hline
\end{tabular}
results shown in table 1 .

TABLE 1 2007-2011 CHINA PROVINCIAL REAL ESTATE DEVELOPMENT EFFICIENCY CALCULATED RESULTS 
Note: TE is technical efficiency; SE is scale efficiency; irs represent increasing returns to scale; drs represent decreasing returns to scale; -represent constant returns to scale

From 2007 to 2011, the provincial real estate development efficiency calculated results, the development efficiency of provincial average of 0.8558 , mainly distributed in the range of $[0.5,1.0]$, explain efficiency of real estate development in general is good, a reasonable allocation of resources, but there are nearly $20 \%$ of the ascension space; Efficiency of various provinces and cities real estate development level are quite different, Shanghai is the highest average level of 2.2225, the lowest in Shanxi Province is only 0.4917; Eastern, Central and Western regions continued to narrow the gap between levels of the development efficiency, efficiency gap within regional internal provinces are 1.6741, 0.3299, 0.9036. By the SE-DEA analysis, six provinces of development enterprises reached technology effectively, including Shanghai technology effectively reached $222.25 \%$, but technology accounted for under $20 \%$ of the overall efficiency effectively, indicating that the input and output efficiency of real estate development enterprises is not high. In addition to the DEA efficient decision-making unit, 21 provincial real estate development enterprises in scale decline stage, the scale efficiency average of 0.7374 , the scale decreasing efficiency accounted for $59.12 \%$, indicating that the majority of provincial real estate development enterprises through the integration of resources has the potential to improve the efficiency of scale, to a certain extent.

\section{B. Based on the Tobit model development efficiency factors} influencing analysis

\section{1) The research hypothesis}

By means of the SE-DEA this paper has obtained municipal real estate development business efficiency values, but what factors affect the efficiency value? To do this we need to further explore. On the whole, selected factors to reflect the main characteristics of provincial real estate development enterprises in China, mainly from the following aspects:

a) Government Support: selecting the financial expenditure proportion of regional GDP to represent the government support influencing factors.

Hypothesis 1: Government support positively related to the efficiency of real estate development.

b) Real Estate Scale: selecting real estate enterprises total number to reflect as real estate scale factors influencing factors.

Hypothesis 2: Scale of real estate and real estate development efficiency are related

c) External Demand: selecting the overall output value of the real estate selected regional areas accounted for the proportion of GDP as real estate development level factors indicators.

Hypothesis 3: Demand environment is positively related to the efficiency of real estate development. d) Production Elements Configuration: selecting the area real estate development enterprises in total assets divided by the number of employees as the allocation of production factors influencing factors.

Hypothesis 4: Production elements configuration and efficiency of real estate development are related.

\section{2) Based on Panel Data Tobit model}

Since there is a minimum efficiency rating value threshold 0 , so the data is truncated, if using ordinary least squares regression directly, the model of parameter estimation will be biased and inconsistent. In order to solve such problems, using the Truncated Regression model proposed to analyze, at the same time, combined with the characteristics of panel data, create the following econometric model, and its structure is as follows:

$\mathrm{y}_{i t}=\left\{\begin{array}{cc}a_{i t}+\beta^{T} x_{i t}+e_{i t}, & a_{i t}+\beta^{T} x_{i t}+e_{i t} \geq 0 \\ 0 & ,\end{array}\right.$

Among them, be explained variable $\mathrm{y}$ as $i$ of 31 provincial, the $t$ year of technical efficiency and scale efficiency(i-1,2,..,31; $\mathrm{t}=2007.2008, \ldots, 2011) ; \quad$ explanatory variables $x_{i t}=$ (Govern it , Scale it, Demand it, Allocation it), $\beta^{T}$ is the unknown parameter vector, $e_{i t} \sim N\left(0, \sigma^{2}\right)$. This model is the Tobit model, explanatory variables $x_{i t}$ take actual observations, the dependent variable $\mathrm{y}_{i t}$ take the value by in the form of restricted. When $\mathrm{y}_{i t} \geq 0$, take the actual observed value; when $\mathrm{y}_{i t} \prec 0$, the observed values are truncated to $0 . a_{i t}$ is $i$ of provinces and cities, the fixed effect of $t$, for the determination of unknown constants.

In the econometric model, selecting the four explanatory variables, these variables may exist the Multicollinearity. So, before the detailed analysis, we must verify whether the explanatory variables exist the Multicollinearity. The specific steps may refer to the above. The results show that the Tolerance of variables are greater than 0.1 , you can roughly determine the Multicollinearity between them is not a serious problem, you can proceed to the next Truncated Regression analysis.

Using the Eviews6.0 software to estimate model, the results are shown in table 2 . 
TABLE 2 THE MODEL REGRESSION RESULTS

\begin{tabular}{|c|c|c|}
\hline variables & $\begin{array}{c}\text { Technical efficiency } \\
\text { of regression model } \\
(1)\end{array}$ & $\begin{array}{c}\text { Scale efficiency of } \\
\text { regression model (2) }\end{array}$ \\
\hline constant & $0.30(1.51) * * *$ & $0.62(4.11) * * *$ \\
\hline Govern $_{\text {it }}$ & $+0.53(2.78) * *$ & $+0.35(2.47) * * *$ \\
\hline Scale $_{\text {it }}$ & $0.15(1.90) * *$ & $+0.04(1.01) * *$ \\
\hline Demand $_{\text {it }}$ & $+1.12(0.13) * * *$ & $+0.40(0.60) * * *$ \\
\hline Allocation $_{\text {it }}$ & $+0.006(2.55) * * *$ & $+0.003(2.35)$ \\
\hline adjR $^{2}$ & 0.83 & 085 \\
\hline D.W. & 2.02 & 2.37 \\
\hline F & 84.16 & 54.07 \\
\hline
\end{tabular}

Note: the variable $\mathrm{t}$ test values are shown in brackets. Significance level: * represent $\mathrm{P}<0.1$, * * represent $\mathrm{P}<0.5$, ** * represent $\mathrm{P}<0.01$.

From the regression results get the following conclusion:

a) Government Support and the technical efficiency and the scale efficiency of real estate significantly positively are related.

b) Scale of Real Estate development had a great effect on technical efficiency and scale efficiency, its coefficient is positive, consistent with hypothesis 2 .

c) External Demand for real estate development technical efficiency also have significant positive effect, the result is consistent with the hypothesis 3 .

d) Model 1 shows that the Production Elements Configuration significantly positively related to real estate development efficiency

\section{CONCLUSIONS}

In view of the above empirical analysis, in order to enhance the level of efficiency of China's provincial real estate development, such points should be paid attention : 1) From the government point of view, more attention should paid to develop the economy, increase financial support for the real estate industry, strengthen appropriate administration guidance of real estate development, prevent develop projects follow like sheep, which easily generate bubble; constantly improve the relevant laws and regulations, standardize the order of the real estate market; guarantee cities real estate develop healthily and orderly, maintain a certain flexibility in the policy, so as to gradually narrow the gap between the level of provinces and cities real estate development efficiency. 2) For enterprise itself, should be based on the enterprise itself and the market demand, the introduction of technology to expand their scale, also constantly improve technical efficiency aspects such as their management level and organization structure etc. to ensure that the limited element into the efficiency of the maximum value.

\section{ACKNOWLEDGEMENTS}

This research was supported by the science foundation of Guangxi University of science and Technology (Grant no. 1307220) and the Doctor Fund of Guangxi University of science and Technology (Grant no. S1103).

\section{REFERENCES}

[1] Danielle Lewis, Randy Anderson. Residential real estate brokerage efficiency and the implications offranchising: A Bayesian approach. Real Estate Economics, 1999, 18(3)

[2] Wei Q L, Zhang X. An inverse DEA model for input/output estimate. European journal of Operational Research, 2000, 24(3):151-163

[3] Yuming $\mathrm{Fu}$, Lilian, $\mathrm{K} \mathrm{Ng}$. Market efficiency and return statistics: Evidence from real estate and stocks market using a present-value approach. Real Estate Economics, 2001, 23(2)

[4] Zhou Chuohua, Li Xuesong. Transformation of the real estate industry listed companies based on DEA efficiency study. Journal of management review, 2007(19): 43-49(in Chinese)

[5] Meng Chuanjin, XingFei, Chen Yu. The efficiency evaluation of real estate enterprises based on DEA analysis. Journal of management review, 2008(7):57-62(in Chinese)

[6] Zheng Junjun, Han xiao, Pan Ziyi. Based on Malmquist Index of real estate development enterprises TFP changes and Convergence study. China soft science, 2013(3):141-151(in Chinese) 